\title{
High Levels of Allergenic Tree Pollen in Southern New Zealand
}

\author{
Rewi M Newnham* \\ School of Geography, Environment and Earth Sciences, Victoria University of Wellington, New Zealand
}

Received: September 07, 2017; Published: September 20, 2017

*Corresponding author: Rewi M Newnham, School of Geography, Environment \& Earth Sciences, Victoria University of Wellington, New Zealand, Email address: rewi.newnham@vuw.ac.nz

\begin{abstract}
Tree Pollen are significant sources of clinically relevant outdoor aeroallergens, a major cause of allergic respiratory diseases, yet little is known about their prevalence in New Zealand. This study reports concentrations of airborne allergenic tree pollen measured in central Dunedin during October and November 1992. Four tree pollen taxa were prominent during these spring months, all from introduced species. Of these, Fraxinus (ash) and Pinus (pine) are not considered to be important aeroallergens, but Betula (birch) and Cupressus (cypress) have reported high allergenic potency in other regions. These results indicate that allergenic tree pollen of birch and cypress can reach significantly high levels in Dunedin during spring, often in association with strong northwesterly winds. It is likely that tree pollen and in particular birch and cypress are making an important contribution to the total pollen allergen load and to the increasing prevalence of allergic rhinitis and asthma in New Zealand. More comprehensive and up-to-date information on allergenic pollen levels is needed to help understand the growing prevalence of respiratory disorder in New Zealand.
\end{abstract}

Keywords: Tree pollen; Allergen; Allergic rhinitis; Allergic asthma; Betula

\section{Introduction}

New Zealand is among the countries with the highest prevalence and morbidity of allergic rhinitis and asthma in the world [1,2], especially amongst children [3]. The high and increasing prevalence in New Zealand and elsewhere remain unexplained but high levels of allergenic pollen and spores are likely candidates. For example, [4] reported comparatively high rates of sensitization to birch pollen as measured by skin tests of adults aged 20-44 years in New Zealand in comparison to other developed countries. Surveys of airborne allergenic pollen in New Zealand to date have largely targeted the summer months and the pollen season for the grasses, the presumed major aeroallergen. As a result, comparatively little is known about the prevalence or allergenic properties of tree pollen in New Zealand, despite their significance in many other regions.

Here, we present daily airborne pollen counts obtained in Dunedin, southern New Zealand during the spring of 1992, showing high levels of cypress (Cupressus) and birch (Betula) pollen from introduced European species with known allergenic properties. These trees have long been established in many regions of New Zealand, particularly in the South Island, and are likely to be important contributors to the comparatively high rates of allergic rhinitis and asthma in New Zealand.

\section{Previous monitoring of airborne pollen in New Zealand}

Despite the high prevalence of respiratory disorder, comparatively few studies of airborne pollen have been undertaken in New Zealand. Early work consisted of single season or single site observations of pollen deposition using rudimentary methods [5-7]. A 15-month survey of airborne pollen in Auckland, was used to compile a pollen calendar portraying the seasonal timing of key allergenic pollens in that city, but recommended that airborne pollen be monitored routinely and at other major population centres [8]. A survey of Pinus pollen dispersal in Palmerston North over a period of three years (1988-1990) showed a distinctive season spanning late July to mid- September, and peaking 2-3 months before the typical grass pollen season in the area [9]. To date, the only geographically-extensive pollen survey was conducted at seven locations simultaneously across New Zealand during the austral summer of 1988/89, but with monitoring primarily restricted to grass pollen [10]. The same data were used subsequently to explore climatic influences in spatiotemporal patterns in these grass pollen data to reveal a latitudinal lag in the timing of season onset [11]. With the exception of the Palmerston North study of pine pollen, none of these papers focused on tree pollen. Recently, a series of publications have reviewed the available information about allergenic pollen levels in Australia and New Zealand and highlighted the emphasis placed to date on grass pollen [12-15]. As such, little is known about the levels of tree pollen in New Zealand, nor the extent to which such pollens could be contributing to the burden of allergenic rhinitis in New Zealand. This study uses data collected in Dunedin to help fill this research gap. 


\section{Methods}

A survey of airborne pollen and spores in Dunedin, New Zealand was undertaken during the spring of 1992 (October 1st to November $30^{\text {th }}$ ). This time period was targeted because, although there was regional-scale information available about grass pollen levels during the summer months [16], no monitoring of the spring flowering phase of the main trees in the region had previously been undertaken. Birch pollen was of particular interest due to its known allergenic properties. The study aimed to identify those plant species which make a significant contribution to Dunedin's airborne pollen levels during the spring period.

An Intermittent Cycling Impaction (Rotorod) sampling device Chapman [17] was installed on the roof of the main cafeteria at the University of Otago campus, in central Dunedin, sited approximately 10 meters above ground level. The device was set up to sample air content for six minutes every hour, with air particles adhering to greased plastic rods. The rods were replaced every 24 hours (72 hours on weekends), stained with Colberla's solution, and examined under a transmitted light microscope at x400 magnification. Raw pollen counts for each of the pollen/spore types identified were converted to the volumetric index (grains $/ \mathrm{m}^{3}$ of air) using a standard formula that takes into account the sampling period and volume of air sampled Chapman [17].

This was the same methodology that had been used recently to record grass pollen levels at seven New Zealand cities [16], thus enabling direct comparison with those results. Pollen identifications were made using the author's reference collection and standard palynological texts. As a general guide to the significance of the pollen levels reported here, a standard used in North America sets a "low" pollen count at up to 15 grains $/ \mathrm{m}^{3}$ air, "moderate" between 15 and 90, and "high" at greater than 90 for all tree pollen (American 90 Academy of Allergy, Asthma and Immunology website).

\section{Results and Discussion}

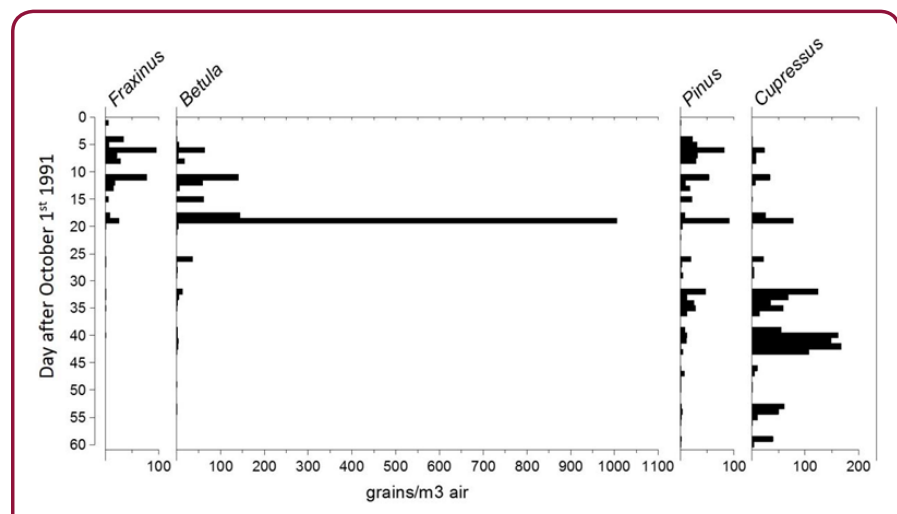

Figure 1: Airborne pollen levels for the four most prominent taxa monitored at Dunedin from October 1st to November 30th 1992.

Of the many pollen types (taxa) observed, most occurred at low and intermittent levels and only four reached moderate levels on any of the days of observation. The daily levels for these four taxa are presented in Figure 1. The figure shows that pollen counts fluctuated markedly from one day to the next, with the highest levels recorded on days when strong northwesterly winds prevailed. Distinct and relatively short pollen seasons are apparent for Fraxinus (mostly F. excelsor) and Betula with longer seasons for the conifers Pinus and Cupressus, likely to be dominated by Pinus radiata and Cupressus macrocarpa (Figure 1).

Of these, according to a European study [18], Fraxinus excelsior rarely induces allergic symptoms and this, combined with the moderate levels of Fraxinus pollen reached suggest that it is unlikely to be a major source of allergic rhinitis in Dunedin. Similarly, pine pollen (Pinus and in this case, mostly $P$. radiata) is not generally considered to be an allergy hazard, despite high levels of pollen production $[9,19]$.

The genus Cupressus, including C. macrocarpa, is widespread in the Mediterranean region where it can contribute a large part of the total annual amount of airborne pollen, due to high rates of pollen production [20]. In the Mediterranean region, the sensitization rate and exposure level to Cupressaceae pollen antigens is highly variable with over $30 \%$ of pollinosis patients reported to be sensitized to Cupressaceae pollen, whilst in the general population, the rate varies from 2.4 to $9.6 \%$ [21]. Interestingly, Cupressus in the Mediterranean is responsible for winter pollinosis when no other allergenic plants are flowering [20,22]. Betula is the major tree pollen allergen in northern and central Europe, where it is one of the principal causes of hay fever and asthma during the spring [23]. A recent European-wide compilation of airborne pollen data (ranging from Iceland to Greece) showed that birch pollen was the most dominant pollen allergen on a European scale for the period 1990-2009 [24]. This status is due to the abundance and widespread distribution of birch trees, their high pollen productivity and, most importantly, their high allergenic potency. Skin-prick tests show the percentage of subjects with positivity to birch allergens ranging from $5 \%$ in the Netherlands to $54 \%$ in Switzerland [20]. Betula pollen is also capable of long-distance transport and so can potentially originate from a broad region [25-27].

Returning to the Dunedin pollen counts, of particular note is that the two taxa recorded in high levels are also those with strong allergy potential. Another interesting feature is that the high levels of Cupressus (mostly C. macrocarpa) are recorded in the New Zealand spring whereas in the Mediterranean region C. macrocarpa pollen is produced and dispersed in the winter months. As New Zealand airborne pollen monitoring to date has largely ignored the winter months, it remains to be seen whether Cupressus pollen in winter is also important. The high, and occasionally, excessively high, levels of Betula and Cupressus pollen levels are not surprising given that both taxa are high pollen producers and are widely established in cities and in rural districts of New Zealand. Cupressus spp., and in particular, C. macrocarpa are commonly grown as shelter-belts on farms throughout New Zealand, or cultivated as ornamentals in gardens. Two species of Betula are common in New Zealand: $B$. pendulum (silver birch) and B. papyfera (paper birch). Silver birch is especially common in South Island cities such as Dunedin and Christchurch where it has been planted in gardens, parks and along roadsides. 
These results indicate that tree pollen allergy is likely to be significant in New Zealand with Betula and Cupressus important contributors to the total allergenic pollen load. Both are recognized as potent allergens in Europe, and their impact on pollinosis levels in New Zealand could be just as strong, if not stronger, due to their widespread abundance. The excessively high levels of Betula pollen recorded on October $19^{\text {th }} 1992$ are comparable to the highest levels recorded in three UK cities (where birch is the most important tree pollen allergen) over a 15-year period (Figure 2).

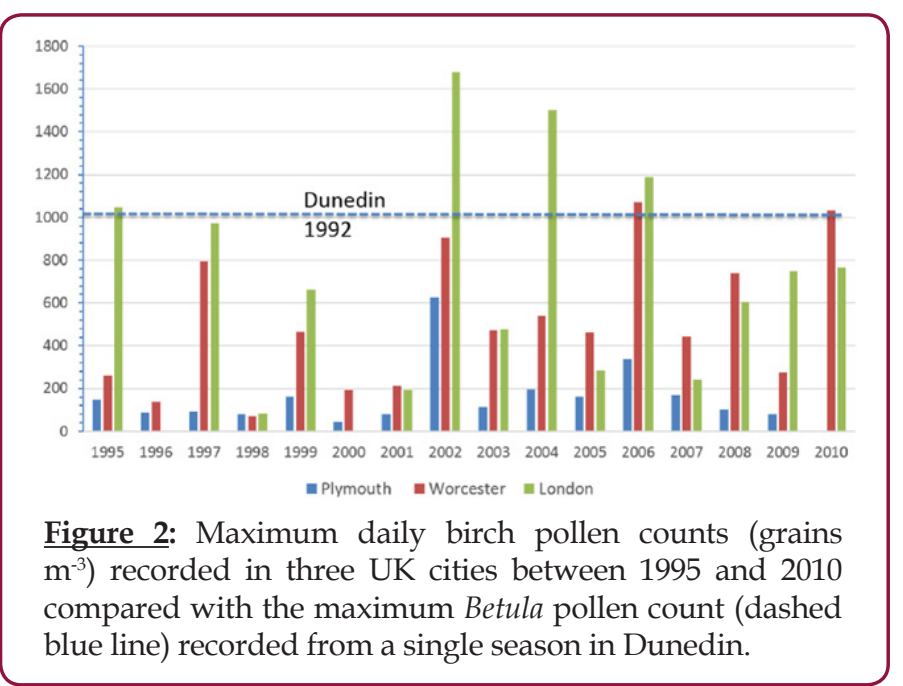

It is interesting to note that the Betula pollen maximum level that occurred on November $19^{\text {th }}$, was an order of magnitude higher than the next highest level, and occurred in association with strong northwesterly winds. The 'Nor-Wester' occurs frequently in the eastern districts of the South Island during spring and summer, bringing hot, dry, windy conditions that have been linked to increased morbidity in the region [28]. These results indicate that the source area and the long-distance dispersal of allergenic pollen can be greatly enhanced by Nor-Westers, adding significantly to the allergenic pollen load in eastern South Island cities and contributing to the cumulative health impacts in those communities (Figure 2).

In Europe, increasing sensitization to both Cupressus and Betula in recent years has been reported $[20,29,30]$ and attributed to a number of factors, including climate change promoting pollen production and dispersal and an earlier seasonal onset [10], as well as their growing popularity as ornamental, garden and landscape plants. The same factors apply in New Zealand [31]. The cross reactivity between these taxa and the other tree pollen allergens and with food allergens is also well documented for Europe [20,24, 31] and for New Zealand [19].

\section{Conclusion}

a. Tree pollen levels, including the allergenic taxa birch and cypress, can reach significantly high levels in Dunedin during the spring months.

b. It is highly likely that this tree pollen is making an important contribution to the total pollen allergen load and to the increasing prevalence of allergic rhinitis and asthma in New Zealand. c. Allergenic pollen can be increased to very high levels during periods of strong northwesterly winds, a pervasive feature of the spring and summer months in eastern South Island districts.

d. This study shows that more comprehensive and up-todate information on allergenic pollen levels is needed to help understand the growing prevalence of asthma and allergic rhinitis in New Zealand and to help facilitate advances in the clinical and public health management of these diseases.

\section{References}

1. Asher MI, Montefort S, Björkstén B (2006) the ISAAC Phase Three Study Group. Worldwide time trends in the prevalence of symptoms of asthma, allergic rhino conjunctivitis, and eczema in childhood: ISAAC Phases One and Three repeat multicounty cross-sectional surveys. Lancet 368(9537): 733-743.

2. Telfar Barnard L, Baker M, Pierse N, Zhang J (2015) The impact of respiratory disease in New Zealand: 2014 update. Wellington: Asthma Foundation.

3. Björkstén B, Clayton T, Ellwood P, Stewart A, Strachan D, et al. (2008) Worldwide time trends for symptoms of rhinitis and conjunctivitis: Phase III of the International Study of Asthma and Allergies in Childhood. Pediatric Allergy \& Immunolog 19(2): 110-124.

4. Bousquet PJ, Chinn S, Janson C, Kogevinas M, Burney P, et al. (2007) Geographical variation in the prevalence of positive skin tests to environmental aeroallergens in the European Community Respiratory Health Survey I. Allergy 63(2): 301-309.

5. Filmer DW, Harris WF, Botany Division, Wellington (1949) Botanical aspects of hay fever in Wellington. Trans R Soc NZ 77: 186-187.

6. Clark HE (1951) An atmospheric pollen survey of five centres in the North Island, New Zealand. NZ J Sci Technol 33(B): 73-91.

7. Licitis R (1953) airborne pollen and spores sampled at 5 New Zealand stations, 1951-1952. NZ J Sci Technol 34(4): 289-316.

8. Hillas JL, Wilson JD (1978) A survey of airborne pollen and spores in Auckland: its use in the diagnosis of seasonal allergies. NZ Medical Journal 628: 37-40.

9. Fountain DW, Cornford CC (1991) Aerobiology and alleregenicity of Pinus radiata pollen in New Zealand. Grana 30: 71-75.

10. Newnham RM, Fountain DW, Cornford CC, Forde MB (1995) A national survey of airborne pollen and grass flowering in New Zealand, with implications for respiratory disorder. Aerobiologia 11: 239-252.

11. Newnham RM (1999) Monitoring biogeographical response to climate change: the potential role of aeropalynology. Aerobiologia 15(2): 87-94.

12. Haberle SG, Bowman DMJS, Newnham RM, Fay H Johnston, Paul J Beggs, et al. (2014) The macroecology of airborne pollen in Australian and New Zealand urban areas. PLoS ONE e97925.

13. Beggs PJ, Katelaris CH, Medek D, Johnston FH, Burton PK, et al. (2015) Differences in grass pollen allergen exposure across Australia. Aust N Z J Public Health 39(1): 51-55.

14. Davies JM, Beggs PJ, Medek D, Newnham RM, Erbas B, et al. (2015) Trans-disciplinary research in synthesis of grasspollen aerobiology and its importance for respiratory health in Australasia. Sci Total Environ 534: 85-96.

15. Medek D, Beggs PJ, Erbas B, Alison K, Jaggard Bradley C, et al. (2015) Regional and seasonal variation in airborne grasspollen levels between cities of Australia and New Zealand. Aerobiologia 32(2): 289-302.

16. Newnham RM, Sparks TH, Skjøth CA, Head K, Adams-Groom B, et al. (2013) Pollen season and climate: is the timing of birch pollen release in the UK approaching its limit? Int J Biometeorol 57(3): 391-250. 
17. Chapman JA (1982) the enhancement of the practice of clinical allergy with daily pollen and spore counts. Immunol. Allergy Pract 4: 13-18.

18. Hemmer W, Focke M, Wantke F, Götz M, Jarisch R, et al. (2000) Ash (Fraxinus excelsior)-pollen allergy in central Europe: specific role of pollen panallergens and the major allergen of ash pollen, Fra e 1. Allergy 55(10): 923-930.

19. Spellerberg IF, Eriksson NE, Crump VS (2006) Silver Birch (Betula pendula) Pollen and Human Health: Problems for an Exotic Tree in New Zealand. Arboriculture \& Urban Forestry 32(4): 133-137.

20. D’Amato G, Cecchi L, Bonini S, Nunes C, Annesi-Maesano I, et al. (2007) Allergenic pollen and pollen allergy in Europe. Allergy 62(9): 976-990.

21. Charpin D (2005) Allergy to cypress pollen. Allergy 60(3): 293-301.

22. Caramiello R, Gallesio MT, Siniscalco C, et al. (1991) Aerobiological data and clinical incidence in urban and extra urban environments. Grana 30: 109-112.

23. Spieksma FThM (1991) Regional European pollen calendars. In: D’Amato G,Spieksma FThM, Bonini S editors. Allergenic pollen and pollinosis in Europe. Oxford: Blackwell Sci Publ 49-65.

24. Smith M, Jäger S, Berger U, Sikoparija B, Hallsdottir M, et al. (2014) Geographic and temporal variations in pollen exposure across Europe. Allergy 69(7): 913-923.

25. Corden J, Stach A, Millington W (2002) A comparison of Betula pollen seasons at two European sites; Derby, United Kingdom and Poznan, Poland (1995-1999). Aerobiologia 18(1): 45-53.
26. Skjøth CA, Sommer J, Stach A, Smith M, Brandt J (2007) The long range transport of birch (Betula) pollen from Poland and Germany causes significant pre-season concentrations in Denmark. Clin Exp Allergy 37(8): 1204-1212.

27. Khwarahm N, Dash J, Skjøth C, B Adams Groom, Eric Caulton, et al. (2014) Exploring the spatio-temporal relationship between two key aeroallergens and meteorological variables in the United Kingdom. Int J Biometeorol 58(4): 529-545.

28. Botica S (2012) An ill wind: Could that nor'wester affect the health of Cantabrians in the future? New Zealand Health Research Council News 76: 1-6.

29. Troise C, Voltolini S, Del Buono G, Negrini AC (1996) Allergy to pollens from Betulaceae and Corylaceae in a Mediterranean area (Genoa, Italy). A ten-year retrospective study. J Investig Allergol Clin Immunol 2(6): 313-317.

30. American Academy of Allergy, Asthma and Immunology website: http:// www.aaaai.org/global/nab-pollen-counts/reading-the-charts.

31. Eriksson NE, Formgren H, Svenonius E (1982) Food hypersensitivity in patients with pollen allergy. Allergy 37(6): 437-443.

32. Khwarahm N, Dash J, Skjøth C, Newnham RM, Adams Groom B, et al. (2017) Mapping the birch and grass pollen seasons in the UK using satellite sensor time-series. Science of the Total Environment 578: 586238.

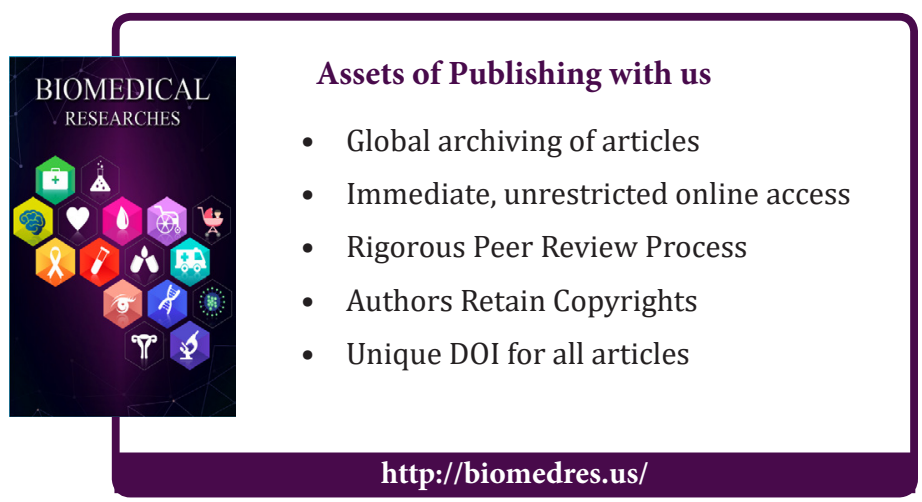

